\title{
Triphasic Waves During Post-Ictal Stupor
}

\author{
Abayomi Ogunyemi
}

\begin{abstract}
Background: The term, "triphasic wave" originally described an EEG pattern believed to be a marker for a specific stage of hepatic coma. For 4 decades, the diagnostic and prognostic specificity of the pattern remains controversial. Its pathophysiology also continues to be elusive. Methods: EEG recordings were obtained in three patients known or suspected to have primary generalized epilepsy. In 2 patients, the EEGs were part of long-term monitoring using simultaneous videoEEG telemetry. For the third patient, the EEG was secured only during the post-ictal unconsciousness. These 3 patients were specifically selected because of the presence of triphasic waves in their EEGs. Results: Triphasic waves were observed in the EEG of the 3 patients only during post-ictal unconsciousness. The pattern was transient, being preceded by generalized suppression and delta slow waves and followed by theta activities. Alpha rhythms supervened when the patients became fully alert. Conclusion: A post-ictal state should be considered in unconscious patients with triphasic EEG waves.
\end{abstract}

\begin{abstract}
RÉSUMÉ: Ondes triphasiques pendant la stupeur postcritique. Introduction: On parlait initialement d'onde triphasique pour décrire un motif EEG qu'on croyait être un marqueur d'un stade spécifique du coma hépatique. Pendant 4 décennies, la spécificité diagnostique et pronostique de ce motif sont demeurées un sujet de controverse. Sa pathophysiologie demeure également obscure. Méthodes: Nous avons obtenu des enregistrements EEG chez trois patients avec un diagnostic certain ou soupçonné d'épilepsie généralisée primaire. Chez 2 patients, l'EEG faisait partie du suivi à long terme associé à la télémesure vidéo-EEG. Chez le troisième patient, l'EEG a été enregistré seulement pendant la période d'inconscience postcritique. Ces 3 patients avaient été choisis à cause de la présence d'ondes triphasiques à l'EEG. Résultats: Les ondes triphasiques ont été observées sur l'EEG des 3 patients seulement pendant la période d'inconscience postcritique. Le motif était transitoire, précédé d'une suppression généralisée et d'ondes delta lentes, et suivi d'activité thêta. Les rythmes alpha sont réapparus quand les patients ont été tout à fait réveillés. Conclusion: On doit considérer qu'il peut s'agir d'un état postcritique chez les patients qui sont inconscients et qui ont des ondes EEG triphasiques.
\end{abstract}

Can. J. Neurol. Sci. 1996; 23: 208-212

The label "triphasic wave" was coined by Bickford and Butt" who opined that the pattern was an EEG marker for a specific stage of hepatic coma. Five years earlier, Foley, Watson and Adams ${ }^{2}$ used the term "blunt spike and wave" occurring at 2 per second for a similar EEG pattern in patients with hepatic encephalopathy. Subsequent investigations reported triphasic waves in non-hepatic conditions such as: drug intoxication, renal failure, anoxic encephalopathy, hypercalcemia, hypoosmolar states, dementia and even brainstem strokes. ${ }^{3-12}$

Bickford and Butt ${ }^{1}$ speculated that triphasic waves may be encountered in patients with convulsive disorders. We are unaware of previous observation of the pattern as a post-ictal phenomenon. We report the occurrence of triphasic waves in the EEG of three patients during post-ictal unconsciousness. This observation suggests that the pattern represents dysfunction of the diffuse thalamocortical system.

\section{Report of Cases}

\section{Patient I}

This 43-year-old woman began to have absence seizures at the age of 6 years. At age 14 generalized tonic clonic seizures developed. The seizures remained uncontrolled, in part, because of non-compliance with the anti-epileptic medications. She has no history of alcohol abuse or liver disease.

She was brought to the Emergency Room at the Health Sciences Centre, St. John's; after having 2 successive grand mal seizures. Upon arrival in the hospital, she was unconscious but did not exhibit tonic, clonic or automatic movements. She withdrew the extremities to pain but did not obey verbal commands. The neurological examination was otherwise unremarkable but for the presence of Babinski response, bilaterally. The examination of the cardiovascular and respiratory systems as well as the abdomen revealed no abnormalities. There was no clinical evidence of hepatic dysfunction.

Two hours after arrival in hospital, she remained stuporous. Emergency EEG recording was then obtained. This revealed diffuse arrhythmic delta slow waves with intermittent, diffuse, frontally-maximum, bisynchronous triphasic waves. Over the ensuing 3-4 hours there was gradual improvement in her level of consciousness. A repeat EEG about 24 hours after admission, when the patient was fully alert, was normal.

From the Division of Neurology, Health Sciences Centre and Faculty of Medicine. Memorial University. St. John's.

RECEIVED AUGUST 29, 1995. ACCEPTED IN FINAL FORM MARCH 5, 1996.

Reprint requests to: Dr. Abayomi Ogunyemi, Division of Neurology, Health Sciences Centre, 300 Prince Philip Drive, St. John's, Newfoundland, Canada A1B 3V6 
Laboratory investigations including complete blood counts, serum biochemical measurements and liver function tests were normal. Toxic screen was not performed.

\section{Patient 2}

This 30-year-old man has had stereotypic seizures since the age of 12 years. These consisted of repetitive jerking of the right arm for $30-90$ seconds, followed by loss of consciousness and generalized tonic and clonic movements. Antiepileptic monotherapy failed to control the seizures.

The general medical examination and neurological examination were normal. Interictal EEG showed normal background activities and intermittent bursts of generalized $3.5-4.5 \mathrm{~Hz}$ spike and slow wave discharges.

Telemetered long-term video-EEG recorded two similar seizures. Each began with repetitive jerking of the right arm, followed a few seconds later by jerking of the left arm, with retention of consciousness. About 70 seconds after onset of the clonic jerking, grand mal seizure developed for 65 seconds followed by post ictal stupor.

The simultaneous EEG showed repetitive generalized spike and wave during the myoclonic jerking of the arms [Figure 1]. Postictally, the EEG demonstrated in succession: generalized suppression, diffuse delta waves and bisynchronous triphasic waves [Figure 2]. The latter was present only for about 110 seconds. Thereafter, the tracing gradually normalized as the patient became alert.

\section{Patient 3}

This 26-year-old man had generalized tonic clonic seizures which persisted despite antiepileptic drugs. The medical history was otherwise unremarkable. In particular, he did not abuse alcohol or illicit drugs and had no history of liver disease. His physical examination was normal. The interictal EEG showed normal background rhythms and sporadic generalized spike and slow wave discharges.

Two typical grand mal seizures were recorded by long-term videoEEG monitoring, demonstrating bilateral and simultaneous onset of the clinical and electrographic changes. The post-ictal EEG showed successively: generalized suppression, low amplitude delta waves, intermittent bisynchronous triphasic waves, diffuse theta and then alpha rhythms.

\section{Discussion}

Uncertainty remains about the diagnostic specifity and pathophysiological mechanism of the triphasic wave. With regard to the morphology, most investigators use many of the criteria described by Bickford and Butt.' More recently, Sundaram and Blume ${ }^{10}$ provided details of the electrographic characteristics of the pattern.

\section{Clinical significance and prognosis of triphasic waves}

Bickford and Butt ${ }^{1}$ placed a poor prognostic stamp on the triphasic wave pattern: of 13 patients with hepatic coma and triphasic waves, eleven died within one week of recording. The others survived for 6 weeks and $2 \frac{1}{2}$ months. The authors described 3 EEG stages of unconsciousness in their patients: (i) delta, (ii) triphasic and (iii) theta.

While it is accepted that delta and theta waves are non-specific, occurring during hyperventilation and conditions of reduced vigilance of diverse etiology, many others still attribute the triphasic wave only to hepatic coma or metabolic encephalopathy. ${ }^{4,6}$
MacGillivray and Kennedy ${ }^{7}$ found no correlation between triphasic waves and pathological diagnosis. Similarly Sundaram and Blume ${ }^{10}$ detected the pattern in both metabolic and nonmetabolic conditions. As we found the triphasic wave to occur during post-ictal stupor in patients with primarily generalized seizures, a specific clinical diagnosis or prognosis cannot be linked to the pattern.

Prognosis more likely depends upon severity of the underlying disease.

\section{Genesis of generalized epileptiform patterns}

Experimental studies implicate the thalamocortical network in the genesis of primarily generalized seizures and their EEG correlates, the generalized spike and wave discharges. ${ }^{13-18}$ Recent observations confirm that the alternating spike and slow wave derive from alternation between low-threshold (T-type) calcium currents and $\mathrm{GABA}_{\mathrm{B}}$ IPSP in thalamic relay neurons ${ }^{19.22}$ causing cyclical depolarization-hyperpolarization in cortical neurons.

\section{EEG features common to the triphasic wave and the gener- alized epileptiform patterns}

The clinical contexts in which the generalized spike and wave and the triphasic wave are observed differ. The former confers susceptibility to primarily generalized seizures while the triphasic wave appear mostly in patients with metabolic encephalopathy. ${ }^{1,2,4-10}$ Nevertheless, the 2 patterns share the following EEG features: (i) generalized or frontal-to-occipital distribution (ii) intermittent occurrence in bursts with variable inter-burst intervals (iii) synchrony and symmetry in homologous regions (iv) voltage predominance in the frontal regions and (v) maximum voltage in the mid-sagittal frontal region.

\section{Pathophysiological significance of triphasic waves}

The similarity in the topographic features between the generalized epileptiform patterns and triphasic waves raise the possibility that the 2 patterns may originate from the same cerebral structures under different clinical conditions. It is not surprising therefore that the triphasic wave may become evident during post-ictal stupor in patients with primary generalized epilepsy.

Sundaram and Blume ${ }^{10}$ found triphasic waves in EEGs containing generalized slow spike and waves. These authors did not describe the temporal relationship of the recordings to the occurrence of seizures. Nevertheless, the coincidence of generalized epileptiform abnormalities and triphasic waves supports the contention that the 2 patterns may have similar anatomopathophysiological substrates.

We observed triphasic wave patterns transiently in the EEG of 3 patients with primary generalized epilepsy who were in post-ictal stupor and who had no clinical or laboratory evidence of metabolic encephalopathy. The possibility of post-ictal unconsciousness should be considered in patients whose EEG recordings show unexplained triphasic waves. 


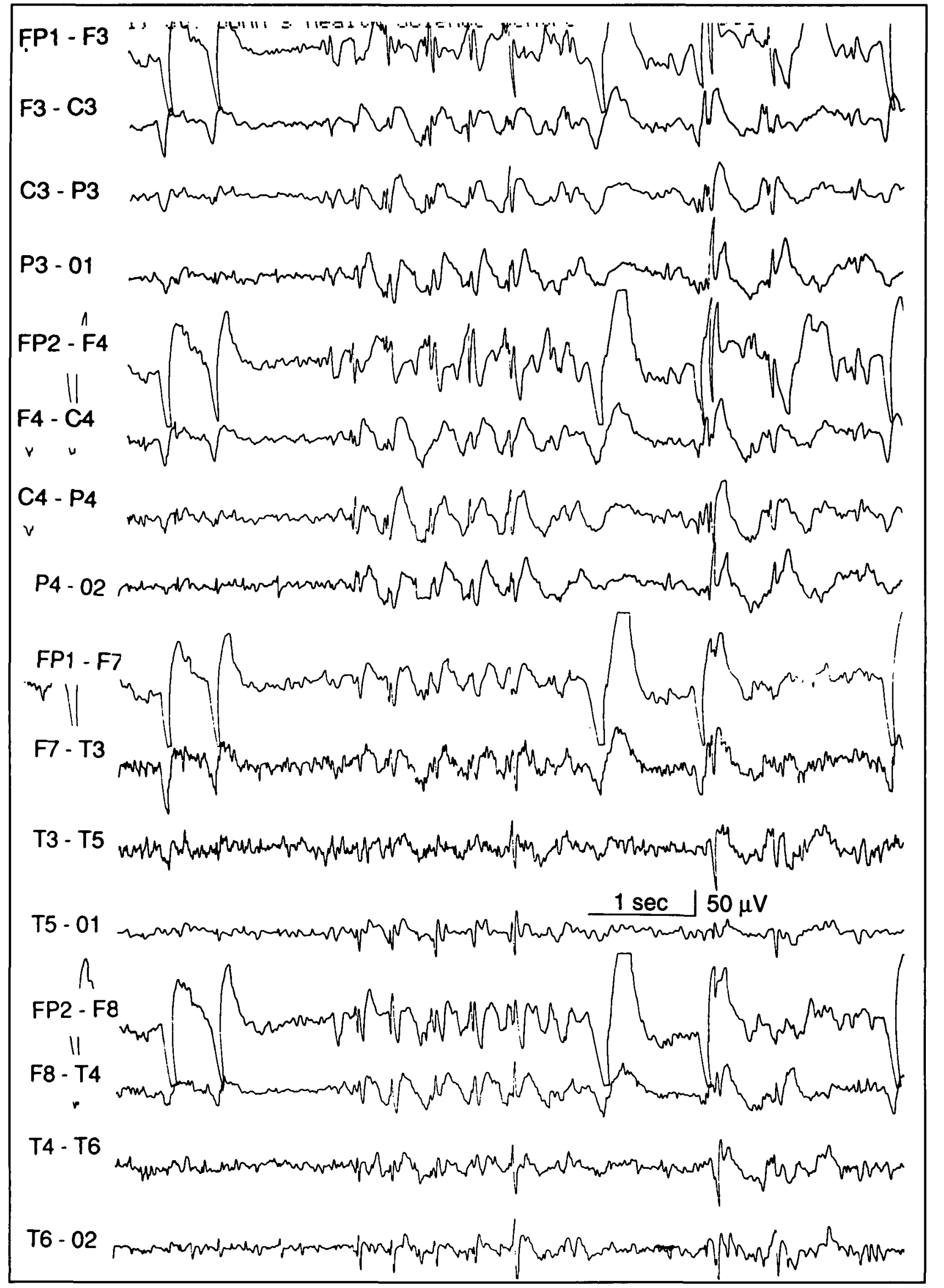

Figure 1: EEG of patient 2 showing generalized, bisynchronous spike and slow waves during myoclonic jerking of the arms. 


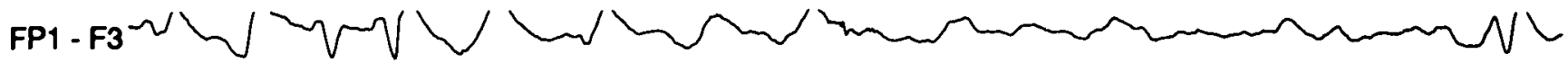
F3-C3 C3 - P3

P3 - 01 FP2 - F4几 F4. $\mathrm{CH}_{4} \mathrm{~W}$ C4.P4

P4- 02 FP1-F7- N F.T3 T3. T5 T5. 01 FP2 - F8V F8-T4 T4-T6 T6-02

Figure 2: EEG of patient 2 showing generalized, bisynchronous triphasic waves during post-ictal stupor. 


\section{REFERENCES}

1. Bickford RG, Butt HR. Hepatic coma: the electroencephalographic pattern. J Clin Invest 1955; 3: 790-799.

2. Foley JM, Watson CW, Adams RD. Significance of the electroencephalographic changes in hepatic coma. Trans Am Neurol Assoc 1950; 75: 161-164.

3. Aguglia W, Gambardella A, Oliveri RL, et al. Non-metabolic causes of triphasic waves. A reappraisal. Clin Electroencephalog 1990; 21: 120-125.

4. Fisch BJ, Klass DW. The diagnostic specificity of triphasic wave patterns. Electroencephalogr Clin Neurophysiol 1988; 70: 1-8.

5. Harner RN, Simsarian JP. Triphasic waves in metabolic encephalopathy. Electroencephalogr Clin Neurophysiol 1974; 36: 222.

6. Karnaze DS, Bickford RG. Triphasic waves: a reassessment of their significance. Electroencephalogr Clin Neurophysiol 1984; 57: 193-198.

7. MacGillivray BB, Kennedy JK. The "triphasic waves" of hepatic encephalopathy. Electroencephalogr Clin Neurophysiol 1970; 28: 428 .

8. Reiher J. The electroencephalogram in the investigation of metabolic comas. Electroencephalogr Clin Neurophysiol 1970; 28: 104.

9. Simsarian JP, Harner RN. Diagnosis of metabolic encephalopathy: significance of triphasic waves in the electroencephalogram. Neurology 1972; 22: 456 .

10. Sundaram MBM, Blume WT. Triphasic waves: clinical correlates and morphology. Can J Neurol Sci 1987; 14: 136-140.

II. Swash M, Rowan AJ. Electroencephalographic criteria of hypocalcemia and hypercalcemia. Arch Neurol 1972; 26: 218-228.

12. Towsend JB, Drury I. Triphasic waves in coma from brainstem infarction. Eur Neurol 1991; 31, 47-49.

13. Jasper HH, Droogleever-Forturn J. Experimental studies on the functional anatomy of petit mal epilepsy. Res Publ Assoc Res Nerv Ment Dis 1946; 26: 272- 278.
14. Pollen DA, Reid KH, Perot P. Microelectrode studies of experimental 3/sec wave and spike in the cat. Electroencephalogr Clin Neurol 1964; 17: 57-67.

15. Pollen DA, Sie PG. Analysis of thalamic induced wave and spike by modification in cortical excitability. Electroencephalogr Clin Neurol 1964; 17: 154-163.

16. Quesney LF, Gloor P, Kratzenberg E, Zumstein H. Pathophysiology of generalized penicillin epilepsy in the cat: the role of cortical and subcortical structures. I. Systematic application of penicillin. Electroencephalogr Clin Neurol 1977; 42: 640-655.

17. Gloor P, Quesney LF, Zumstein H. Pathophysiology of generalized penicillin epilepsy in the cat: the role of cortical and subcortical structures. II. Topical application of penicillin to the cerebral cortex and to subcortical structures. Electroencephalogr Clin Neurol 1977; 43: 79-94.

18. Gloor P. Generalized epilepsy with spike-and-wave discharge. A reinterpretation of its electrographic and clinical manifestations. Epilepsia 1979; 20: 571-588.

19. Crunelli V, Leresche $N$. A role for $\mathrm{GABA}_{B}$ receptors in excitation and inhibition of thalamocortical cells. Trends Neurol Sci. 1991; 14: 16-21.

20. Crunelli V, Lightowler S, Pollard CE. A T-type $\mathrm{Ca}^{2+}$ current underlies low-threshold $\mathrm{Ca}^{2+}$ potentials in cells of the cat and rat lateral geniculate nucleus. J Physiol (Lond) 1989; 413: 543-561.

21. Coulter DA, Huguenard JR, Prince DA. Calcium currents in rat thalamocortical relay neurones: kinetic properties of the transient, low-threshold current. J Physiol (Lond) 1989; 414: 587-604.

22. Coulter DA, Huguenard JR, Prince DA. Characterization of ethosuximide reduction of low threshold calcium current in thalamic neurons. Ann Neurol 1989; 25: 582-593.

23. Huguenard JR, Prince DA. A novel T-type current underlies prolonged $\mathrm{Ca}^{2+}$ - dependent burst firing in GABAergic neurons of rat thalamic reticular nucleus. J Neuroscience 1992; 12: 38043817. 